\title{
Suturing techniques and postoperative management in penetrating keratoplasty in the United Kingdom
}

This article was published in the following Dove Press journal:

Clinical Ophthalmology

14 August 2012

Number of times this article has been viewed

\section{Richard MH Lee' \\ Fook Chang Lam' \\ Tassos Georgiou' \\ Bobby Paul' \\ Kong Yong Then' \\ loannis Mavrikakis' \\ Venkata S Avadhanam' \\ Christopher SC Liu',2}

'Sussex Eye Hospital, Brighton, United Kingdom; ${ }^{2}$ Tongdean Eye Clinic, Hove, United Kingdom
Correspondence: Christopher SC Liu Sussex Eye Hospital, Eastern Road, Brighton BN2 5BF, United Kingdom

Tel +44 I273606 I26

Fax +44 I273 553038

Email cscliu@aol.com
Aims: To report on the suturing techniques and aspects of postoperative management in penetrating keratoplasty in the United Kingdom.

Methods: A postal questionnaire was sent to 137 ophthalmic consultants identified from a Royal College of Ophthalmology database as having a special interest in anterior segment surgery. The questionnaire surveyed surgeon preferences for surgical and suturing technique for penetrating keratoplasty surgery, and the postoperative care of corneal grafts.

Results: In all, $68 \%$ of questionnaires were completed and returned: $73 \%$ of respondents used a Flieringa ring or equivalent, $94 \%$ routinely used cardinal sutures, with $50.5 \%$ removing them at the end of the procedure. The most common suturing technique for routine penetrating keratoplasty was a single continuous suture (35\%). In these cases, a 10/0 nylon suture was used by $89 \%$. Sixty-six percent changed their technique in high-risk cases, $52 \%$ used a 3-1-1 knot, and $75 \%$ made a distinction between a reef and granny knot, with $76 \%$ using a reef. Thirty percent buried the knots within the donor material, and 29\% within the host tissue. Twenty-five percent had no routine time for graft suture removal, but $41 \%$ removed them between 1 and 2 years post-surgery. After suture removal, $98 \%$ used steroids and $88 \%$ used topical antibiotics. Thirtyfour percent stopped topical steroids before suture removal, with 38\% stopping topical steroids more than 3 months prior to suture removal.

Conclusion: This survey demonstrates that there is considerable variation in suturing techniques and postoperative care for penetrating keratoplasty. These significant variations in practice need to be considered when interpreting outcomes and research.

Keywords: corneal graft, penetrating keratoplasty, anterior segment surgery, cornea, corneal surgery, corneal transplantation

\section{Introduction}

The history of penetrating keratoplasty (PK) is almost 100 years old, starting with Elschnig in Prague and later Tudor-Thomas in the United Kingdom. ${ }^{1}$ There have been significant advances in instruments, suture materials, operating microscopes, medication, and surgical techniques used in PK surgery. A total of 2568 PK operations were undertaken in the United Kingdom in 2008-2009. ${ }^{2}$ There are a wide variety of suture techniques employed in corneal transplantation. ${ }^{3,4}$ They include single continuous (radial placement vs no torque), double continuous (same direction vs opposing pattern), interrupted, and a combination of interrupted and continuous sutures. Each technique has its own advantages and disadvantages, and suturing technique is perhaps the area of greatest variation in PK surgery. However, it is important that the surgeon is clear on the reason for their adopting a particular technique with a patient. Postoperative suture 
management is another area where great variation exists between surgeons. We designed this study to survey the suturing techniques and routine postoperative care regimes adopted by anterior segment specialists in the United Kingdom.

\section{Materials and methods}

In 2003, we identified all the consultants in the UK with an interest in corneal surgery from a Royal College of Ophthalmologists database. A postal questionnaire was sent out to 137 surgeons. It covered surgeons' preferences for globe fixation and support for PK surgery (ie, the use of superior and inferior recti sutures, and circumstances in which a Flieringa ring is used), and included questions on the use of cardinal sutures, routine suture technique, whether technique was altered in high-risk cases, and routine postoperative management. The questionnaire was sent only once, and no reminder was posted.

\section{Results}

A total of 93 (68\%) completed questionnaires were returned.

\section{Globe fixation and support}

For globe fixation, $40 \%$ used both inferior and superior rectus traction sutures, $4 \%$ used only superior, and $56 \%$ did not use them. Of those who used recti sutures, 95\% used 4/0 (57\%) and 6/0 (38\%) silk.
For globe support, $73 \%$ of respondents used a Flieringa ring or the equivalent to provide scleral support. Of these respondents, $29.5 \%$ used a ring in all cases, $89 \%$ used a ring in aphakic patients, $33 \%$ in pseudophakic patients, and $4 \%$ in phakic patients. Other situations where a Fleiringa ring was used were pediatric cases, keratoconus, triple procedure, and vitrectomized eyes. The suture used to secure the ring included 6/0 silk (42\%) or 6/0 polyglactin (Vicryl) (42\%).

\section{Routine graft suture technique}

Ninety-four percent of respondents used nylon (10/0 or $6 / 0)$ for their cardinal sutures, and $4 \%$ used silk (6/0 or $8 / 0)$. In $50.5 \%$, the cardinal sutures would be removed at the end of the procedure. Suture technique preference is summarized in Figure 1, respondents using nylon suture material in $89 \%$ and Mersilene in 3\% of cases.

Sixteen bites was the most popular choice for single continuous (39\%) and interrupted (70\%) suturing techniques. For combined interrupted and continuous sutures, $46 \%$ of respondents performed twelve continuous and twelve interrupted bites. In the majority of cases, the first suture is placed at 12 o'clock for cardinal sutures (86\%), continuous $(54 \%)$, and interrupted (76\%) techniques.

Sixty-six percent of respondents reported changing from their usual suturing technique in high-risk cases (ie, vascularized corneas, multiple failed grafts, pediatric cases,

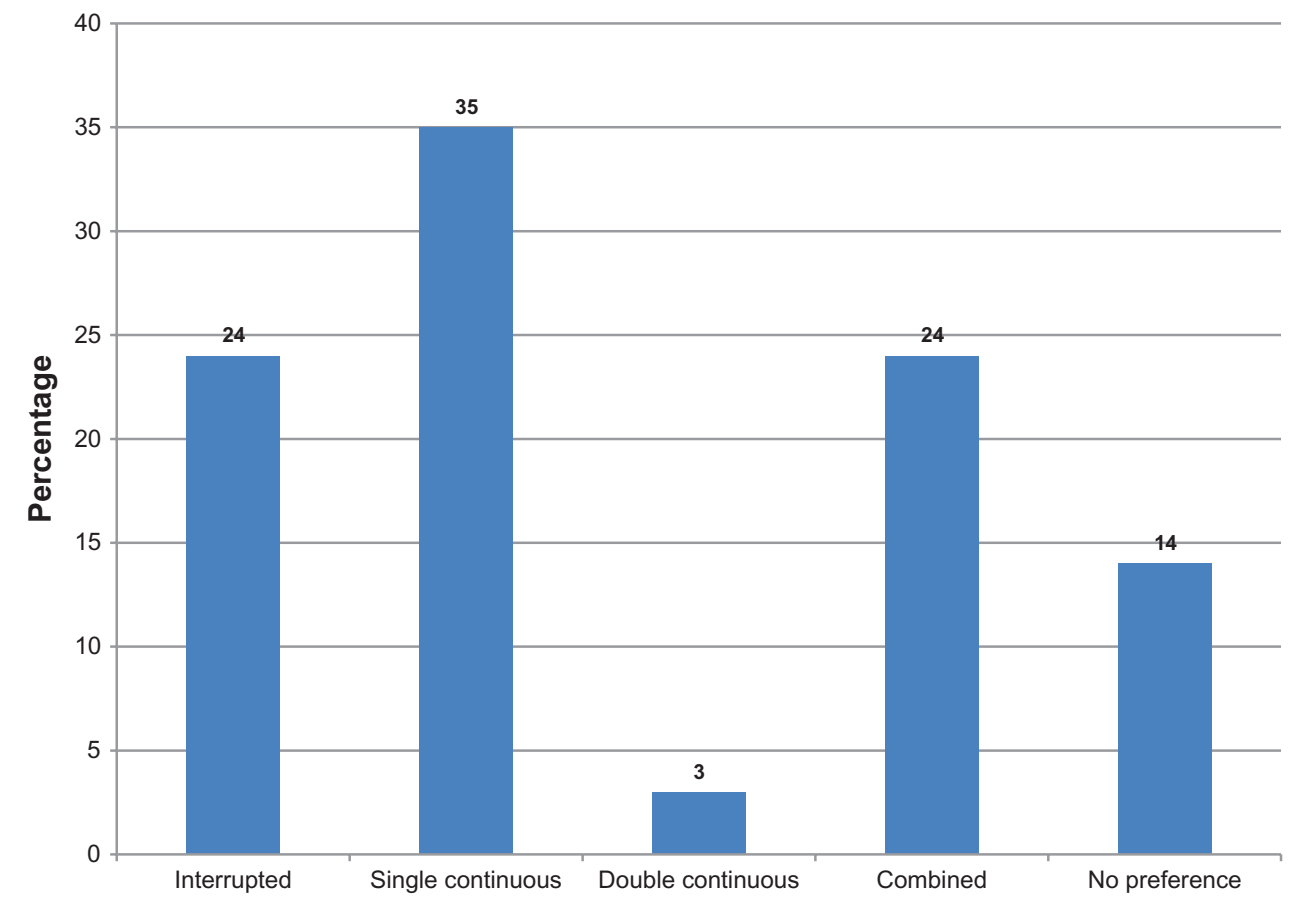

Figure I Respondents' preferences for corneal suturing technique employed. 
therapeutic PK, and inflamed eyes). Of those that altered their techniques, $76(82 \%)$ changed to an interrupted suture technique.

Knot technique is summarized in Figures 2 and 3. Seventy-five percent of respondents made a distinction between using a reef or a granny knot, and $76 \%$ of these respondents used a reef knot. The direction in which surgeons left knot tails facing is summarized in Figure 4.

\section{Routine postoperative management}

The majority (41\%) removed all corneal sutures at $1-2$ years, $24 \%$ removing sutures at 1 year, while $25 \%$ had no specific routine for the removal of graft sutures. When removing the knot, 47/89 (53\%) responded that they pulled the knot through the host side, and 30/89 (34\%) through the donor, with $12 / 89(13 \%)$ replying “either." Seven of $89(8 \%)$ regularly pulled the knot through the interface.

Ninety-eight percent used topical steroids routinely following penetrating keratoplasty, 25\% used topical steroids for 1 week, and 55\% for between 1 week and 1 month, while $16 \%$ used topical steroids for more than 1 month. Eighty-eight percent of respondents used topical antibiotics following suture removal: $57 \%$ for 1 week, and $23 \%$ for 1 week to 1 month.

Thirty-four percent stopped topical steroids before suture removal, $38 \%$ of respondents stopping for more than
3 months before, $16 \%$ replying that their practice varied, and $22 \%$ did not specify for how long.

\section{Discussion}

The aim of this questionnaire survey was to assess trends in PK suturing technique and postoperative care among consultant ophthalmologists registered with the Royal College of Ophthalmologists with a special interest in anterior segment surgery. Lamellar surgery has become increasingly more popular, due to the reduced risk of immune rejection and intraoperative or postoperative complications. ${ }^{5,6}$ However PK surgery is still necessary in situations where there is fullthickness corneal disease. Our survey, performed in 2003, is therefore still relevant and applicable to ophthalmologists today. We had a good response rate (68\%), which is comparable to other surveys on PK technique. ${ }^{3,4}$ Whereas previous surveys have focused more on such aspects of PK surgery as management of additional surgery and type of graft material used, our survey highlights the differences in surgical techniques used and postoperative management.

\section{Globe fixation}

The majority of respondents used a Flieringa ring or equivalent for support, especially in aphakic patients, but also with pediatric cases, keratoconus, vitrectomized eyes or triple procedures. In the pediatric eye, the Flieringa ring acts as

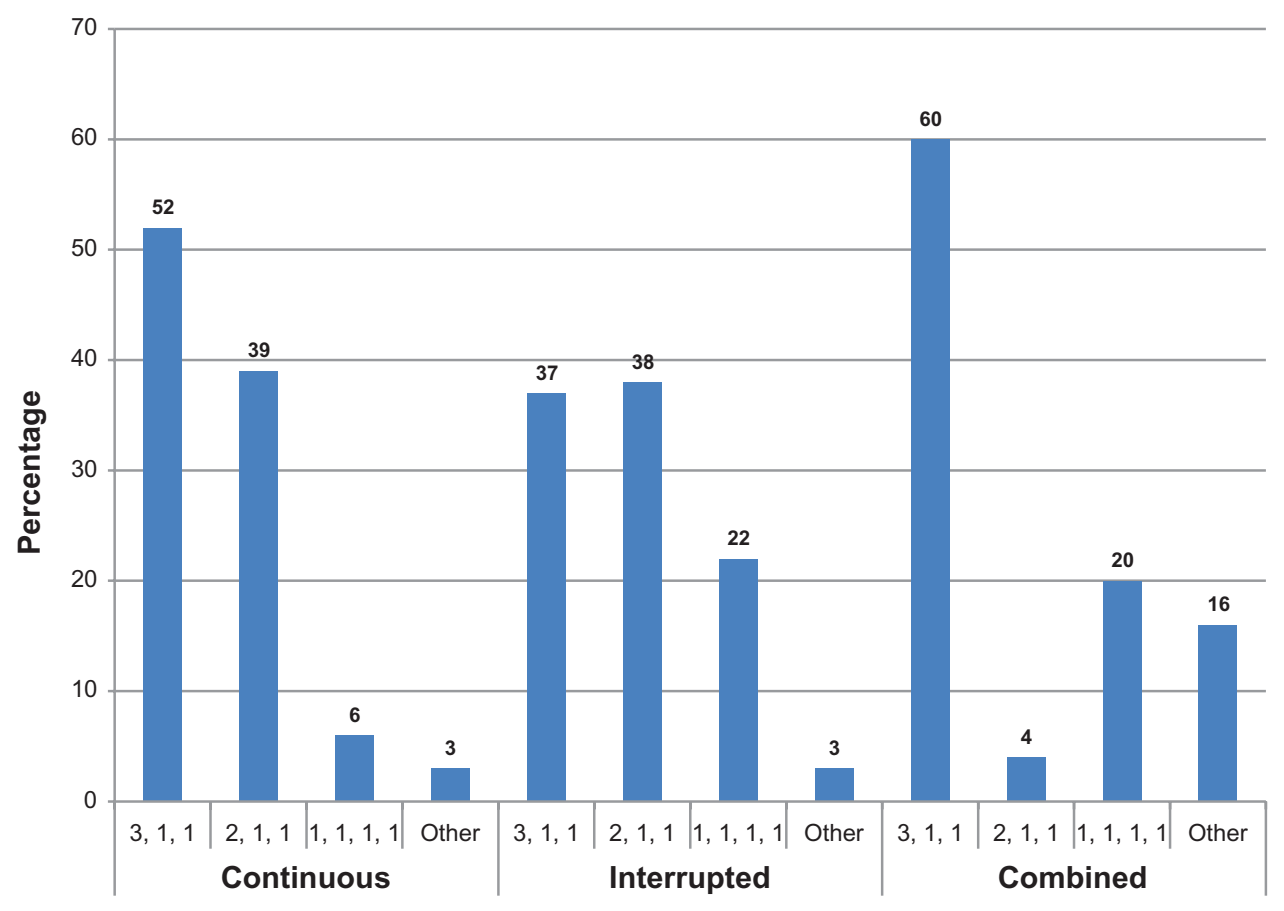

Figure 2 Respondents' preferences for knots employed for different suturing techniques. 


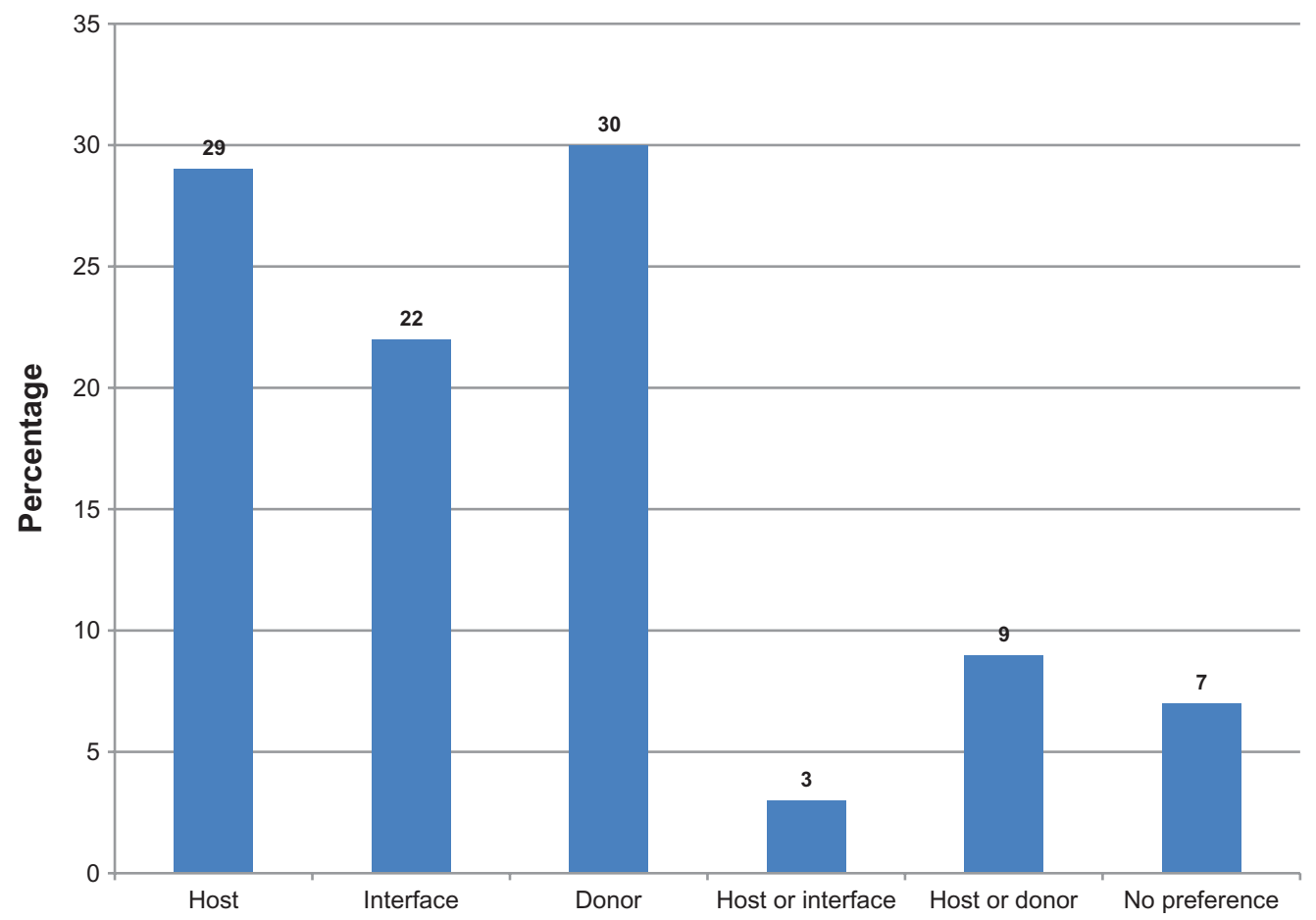

Figure 3 Respondents' preferences for position where knots were buried.

a useful support due to the increased scleral elasticity and reduced rigidity of the eyes. ${ }^{7}$

\section{Suturing technique}

The results show that the most popular suturing technique in PK was single continuous (35\%), comparable to $39 \%$ in the 1992 survey, and the most popular suture material was $10 / 0$ nylon. There is continuing debate regarding which suturing technique is superior. ${ }^{8,9}$ However, other factors that can impact on postoperative astigmatism include patient diagnosis, ${ }^{10}$ tissue distribution, and preexisting donor shape, rather than suture pattern. Other advantages of using
A

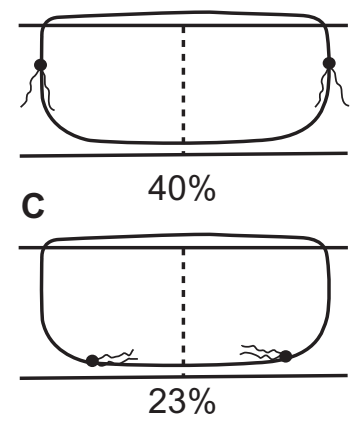

B

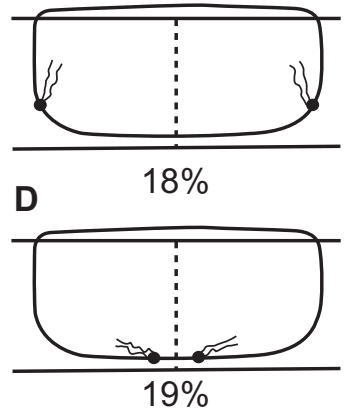

Figure 4 Illustration of respondents' preference for placing the direction of the tails of the knots: (A) facing away from the ocular surface; (B) facing towards the ocular surface; (C) facing towards the graft-host interface; (D) facing away from the grafthost interface. continuous sutures are the ease of placement of sutures, the ability to adjust loop tension intraoperatively as well as in the immediate postoperative period for reduction of astigmatism, and the presence of fewer knots that may irritate and induce vascularization.

The disadvantage of the continuous suture technique is the potential for corneal graft wound dehiscence if the suture should break, especially if only a single continuous suture has been used. Experimental studies on animal models have suggested that interrupted sutures have faster wound healing and a greater stromal inflammatory response, although there was no difference in blowout pressure between either suturing technique when comparing wound strength. ${ }^{11}$ Another study has suggested from its experimental model of wound closure that a continuous suture offers better wound closure than interrupted sutures. ${ }^{12}$ However, in our survey, $82 \%$ used interrupted sutures in high-risk cases. This is a much higher response than the 1992 paper, where only $28 \%$ of consultants altered their suturing technique. ${ }^{3}$

In our survey, only three respondents (3\%) used Mersilene. These surgeons used the 11/0 Mersilene interrupted sutures. Mersilene is a non-biodegradable material with minor long term changes in postoperative astigmatism, unlike nylon sutures, which have a tendency to break. ${ }^{13}$ Mersilene sutures are associated with a higher risk of complications and interventions to correct suture-related problems in the first year 
postoperatively, but fewer suture-related complications have been observed at 2 years. ${ }^{14}$

The vast majority of surgeons (75\%) make a distinction between reef and granny knot. Hammond et al demonstrated with electron microscopy that a 2-1-1 nylon reef knot was a slim knot that allowed easier knot burial and atraumatic suture removal, thus reducing the risk of wound dehiscence. ${ }^{15}$ The way in which the knots are buried can determine how easily they can be removed later on. It is generally undesirable to drag the knot through the graft-host interface, and we would recommend that the knots should not be buried at the interface.

\section{Postoperative care}

Although $25 \%$ of surgeons had no set routine for suture removal, $68 \%$ tended to remove them within 2 years. In the 1992 survey, ${ }^{3}$ a greater proportion of respondents had no set routine for suture removal (44\%), although removal of sutures was comparable with our survey at 1 year $(24 \%$ vs $33 \%)$ and at 2 years ( $8 \%$ vs $7 \%)$. In our survey, $34 \%$ stopped topical steroids before suture removal, ranging from 1 week to more than 3 months. There is ongoing debate as to whether topical steroids impair wound healing. In some animal studies, reduced fibroblastic response and impaired wound healing have been found, ${ }^{16}$ whereas in others no difference was found when compared with a placebo. ${ }^{17}$ However, in keeping with other surveys of postoperative care, the majority of surgeons in our survey used topical steroids following PK, although the duration of treatment was variable. ${ }^{18}$

Graft rejection can occasionally occur following removal of sutures, ${ }^{19}$ and consequently $98 \%$ of respondents tended to cover such risk by giving topical steroid. Most $(80 \%)$ were given for up to a 1-month period. The removal of corneal sutures can also increase the risk of wound dehiscence following trauma. ${ }^{20}$ However long-term sutures can become loose or break with time, and this is associated with microbial keratitis, which can result in a failed graft or reduced visual acuity. ${ }^{21}$ We found that the majority of surgeons tended to cover suture removal with antibiotic prophylaxis to try and prevent this.

We would recommend using a Flieringa ring for support in certain circumstances such as aphakic eyes, pseudophakic eyes, or those eyes to be rendered aphakic or pseudophakic as part of the procedure, and pediatric eyes. While surgeons can choose freely between single continuous or interrupted sutures, we would recommend the latter for high-risk cases such as children and hot eyes (infection and inflammation), as there will be a high risk of early suture loosening.
We consider 10-0 monofilament nylon superior to other suture material. Except where tension is important, such as the four cardinal sutures, we would recommend a 2-1-1 knot (preferably reef), as it has a small profile that allows for easier knot burial and atraumatic suture removal at a later date. Although there is debate as to which side of the interface the knot should be buried, it is certainly undesirable to pull the knot through the interface. Topical steroids should be stopped before suture removal, but then should be reinitiated with topical antibiotic cover after removal of sutures.

Limitations of this study include the fact that it was performed only in the United Kingdom and therefore may not be applicable to other parts of the world. We also did not assess for differences in surgical techniques and postoperative management in lamellar graft surgery, although this is being planned for our next study, which is about to commence.

\section{Conclusion}

The results of this survey provide a snapshot of surgical techniques preferred by corneal surgeons for PK in the United Kingdom, and demonstrate that a great degree of variation exists in PK techniques and postoperative management of corneal grafts. These significant variations in practice need to be considered when interpreting outcomes and research.

\section{Disclosure}

No financial support was received for this submission. None of the authors has any conflict of interest with this work.

\section{References}

1. Foster CS, Azar DT, Dohlman CH, editors. Smolin and Thoft's the Cornea: Scientific Foundations and Clinical Practice. Philadelphia: Lippincott Williams \& Wilkins; 2004.

2. UK transplant activity 2008-2009 report. Available at: http://www. organdonation.nhs.uk/ukt/statistics/transplant_activity_report/ archive_activity_reports/pdf/ukt/transplant_activity_uk_2008-2009.pdf. Accessed June 19, 2011.

3. Burdon MA, McDonnell P. A survey of corneal graft practice in the United Kingdom. Eye (Lond). 1995;9(Pt 6 Suppl):6-12.

4. Steven P, Winter R, Geerling G. Current state of mechanical corneal surgery - results of a questionnaire to members of the cornea section of the German Society of Ophthalmologists. German. Klin Monbl Augenheilkd. 2006;223(10):844-848.

5. Tan DT, Anshu A, Mehta JS. Paradigm shifts in corneal transplantation. Ann Acad Med Singapore. 2009;38(4):332-338.

6. Reinhart WJ, Musch DC, Jacobs DS, Lee WB, Kaufman SC, Shtein RM Deep anterior lamellar keratoplasty as an alternative to penetrating keratoplasty: a report by the American Academy of Ophthalmology. Ophthalmology. 2011;118(1):209-218.

7. Vanathi M, Panda A, Vengayil S, Chaudhuri Z, Dada T. Pediatric keratoplasty. Surv Ophthalmol. 2009;54(2):245-271.

8. Solano JM, Hodge DO, Bourne WM. Keratometric astigmatism after suture removal in penetrating keratoplasty: double running versus single running suture techniques. Cornea. 2003;22(8):716-720. 
9. Kim SJ, Wee WR, Lee JH, Kim MK. The effect of different suturing techniques on astigmatism after penetrating keratoplasty. J Korean Med Sci. 2008;23(6):1015-1019.

10. Claesson M, Armitage W J, Fagerholm P, Stenevi U. Visual outcome in corneal grafts: a preliminary analysis of the Swedish Corneal Transplant Register. Br J Ophthalmol. 2002;86(2):174-180.

11. Eliason J, McCulley J. A comparison between interrupted and continuous suturing techniques in keratoplasty. Cornea. 1990;9(1):10-16.

12. Au YK, Mahjoub S, Hart J. A comparison of the wound integrity produced by various suture patterns in penetrating keratoplasty: a cadaver eye model. Ophthalmic Surg. 1990;21(2):123-125.

13. Bartels MC, van Rooij J, Geerards AJ, Mulder PG, Remeijer L. Comparison of complication rates and postoperative astigmatism between nylon and mersilene sutures for corneal transplants in patients with Fuchs endothelial dystrophy. Cornea. 2006;25(5):533-539.

14. Landau D, Siganos CS, Mechoulam H, Solomon A, Frucht-Pery J. Astigmatism after mersilene and nylon suture use for penetrating keratoplasty. Cornea. 2006;25(6):691-694.

15. Hammond CJ, Chan WY, Liu CS. Scanning electron microscopic study of monofilament suture knots. Br J Ophthalmol. 1996;80:164-167.
16. Barba KR, Samy A, Lai C, Perlman JI, Bouchard CS. Effect of topical anti-inflammatory drugs on corneal and limbal wound healing. J Cataract Refract Surg. 2000;26(6):893-897.

17. McCarey BE, Napalkov JA, Pippen PA, Koester JM, al Reaves T. Corneal wound healing strength with topical antiinflammatory drugs. Cornea. 1995;14(3):290-294.

18. Randleman JB, Stulting RD. Prevention and treatment of corneal graft rejection: current practice patterns (2004). Cornea. 2006;25(3): 286-290.

19. Abou-Jaoude E, Brooks M, Katz D, Van Meter W. Spontaneous wound dehiscence after removal of single continuous penetrating keratoplasty suture. Ophthalmology. 2002;109(7):1291-1296; discussion 1297.

20. Lam FC, Rahman MQ, Ramaesh K. Traumatic wound dehiscence after penetrating keratoplasty - a cause for concern. Eye. 2007;21(9): 1146-1150.

21. Wright TM, Afshari NA. Microbial keratitis following corneal transplantation. Am J Ophthalmol. 2006;142(6):1061-1062.
Clinical Ophthalmology

\section{Publish your work in this journal}

Clinical Ophthalmology is an international, peer-reviewed journal covering all subspecialties within ophthalmology. Key topics include: Optometry; Visual science; Pharmacology and drug therapy in eye diseases; Basic Sciences; Primary and Secondary eye care; Patient Safety and Quality of Care Improvements. This journal is indexed on

\section{Dovepress}

PubMed Central and CAS, and is the official journal of The Society of Clinical Ophthalmology (SCO). The manuscript management system is completely online and includes a very quick and fair peer-review system, which is all easy to use. Visit http://www.dovepress.com/ testimonials.php to read real quotes from published authors. 